\title{
EL USO EXCESIVO DEL DERECHO, \\ UNA FORMA DE VINCULACIÓN \\ ENTRE LA PROPIEDAD INDUSTRIAL
}

\author{
Y LA COMPETENCIA
}

CAMILO HERNÁN CORTÉS PRIETO*

\section{RESUMEN}

La propiedad industrial, como disciplina especializada del Derecho, no se desliga de los conceptos clásicos del derecho de propiedad, sino que los conserva y potencializa gracias su calificación precisamente de industrial. No obstante, debido al alcance de la creatividad humana y las dinámicas del mercado, se han alcanzado objetos de protección mediante la propiedad industrial sobre las formas de los productos en sí mismas, la cuales, al ser protegidas mediante marcas (tridimensionales), le otorgan una exclusividad al titular que puede influir de manera negativa en el tráfico económico y en la competencia cuando dicha forma de producto carece de sustitutos en el mercado que satisfagan las mismas necesidades.

Palabras clave: propiedad industrial; abuso del derecho; posición dominante; uso excesivo; marcas tridimensionales; formas de producto.

\section{THE EXCESSIVE USE OF RIGHTS, A LINK BETWEEN \\ INDUSTRIAL PROPERTY AND COMPETITION}

\section{ABSTRACT}

Industrial property, as a specialized discipline of law, does not separate from the classical concepts and patterns of property law, but rather preserves and enhances

\footnotetext{
* Abogado de Universidad Libre de Colombia (Bogotá). Consultor y litigante en asuntos de propiedad intelectual, competencia desleal y protección al consumidor, con estudios de posgrado en Derecho Comercial y Derecho Procesal Civil de la Universidad Externado de Colombia, Bogotá DC. (Colombia). Correo-e: cortesprieto.camilo@gmail.com. Fecha de recepción: 3 de septiembre de 2020. Fecha de aceptación: 20 de enero de 2021. Para citar el artículo: Cortés Prieto, Camilo Hernán. "El uso excesivo del derecho, una forma de vinculación entre la propiedad industrial y la competencia”, en Revista de la propiedad inmaterial n. ${ }^{\circ}$ 31, Universidad Externado de Colombia, enero-julio 2021, pp. 5-34. DoI: https://doi.org/10.18601/16571959.n31.01
} 
them thanks to its specific industrial qualification. However, due to the scope of human creativity and the dynamics of the market, objects of protection have been achieved through industrial property on the forms of the products themselves, which, when protected by (three-dimensional) brands, give an exclusivity to its owner that can negatively influence economic traffic and competition when said product form lacks substitutes in the market that satisfy the same needs.

Keywords: Industrial property; Abuse of rights; Dominant position; Excessive use; Three-dimensional marks; Product forms.

\section{INTRODUCCIÓN}

En este escrito se analiza la protección de las formas de productos mediante los derechos de propiedad industrial y su influencia en el mercado, con el fin de determinar si la consolidación de derechos exclusivos sobre formas de productos y su posterior uso en el mercado puede configurar un abuso de la posición dominante, un acto desleal en la competencia o un uso abusivo o excesivo del derecho de propiedad.

En el análisis se tendrán en consideración: i) la naturaleza jurídica de la propiedad industrial de acuerdo con los atributos propios del derecho de propiedad clásico, y ii) los presupuestos derivados del calificativo "industrial" de esta disciplina que, más allá de un alcance descriptivo o semántico, permiten comprender la especialidad de ese tipo de derechos que los diferencian de cualquier derecho de propiedad simple o común, especialmente en lo relativo a la vinculación de los derechos de propiedad industrial con el mercado y con la competencia.

Una vez establecidos estos criterios se analiza su incidencia sobre formas de productos mediante registros de marca comercial, los cuales facultan a su titular a excluir de su uso a cualquier tercero que lo explote o reproduzca sin su autorización (ius prohibendi). Así las cosas, se estudia si la facultad de exclusión llevaría a que a otros agentes les sea imposible ingresar al mercado del producto que se trate, generando una incidencia nociva en el mercado cuando se trata de productos que no tienen sustitutos, es decir, cuando no existen otros artículos que remplacen la satisfacción de la necesidad que se obtiene al adquirir el producto protegido con determinada forma.

Finalmente, y una vez comprobado que se genera un efecto negativo en la competencia derivado de la apropiación de una forma de producto singular mediante derechos de propiedad industrial, se examina dicha circunstancia frente a la eventual configuración de uno de los escenarios mencionados desde la óptica del derecho de la competencia - practicas restrictivas y competencia desleal- y desde el uso del derecho de propiedad -abusivo y excesivo-. 


\section{NATURALEZA JURÍDICA DE LOS DERECHOS DE PROPIEDAD INDUSTRIAL}

El derecho industrial o de propiedad industrial ha sido reconocido y denominado principalmente como "derecho de la propiedad industrial", disciplina que, por lo menos hasta finales del siglo xx, comenzó a ser parte del contenido del derecho mercantil y comercial dentro del denominado "patrimonio de la empresa"1 que se encargaba de estudiar los bienes inmateriales que conforman dicho patrimonio ${ }^{2}$. El estudio inicial de la propiedad industrial se reducía al régimen de invenciones industriales y de los signos distintivos como bienes mercantiles del empresario. Sin embargo, otra parte de la doctrina encuadra la propiedad industrial dentro del derecho de la competencia por cuanto "los derechos de propiedad industrial constituyen posiciones privilegiadas que permiten excluir legítimamente a terceros de ciertos sectores de la actividad económica"3.

Tratándose de la naturaleza de los derechos de propiedad industrial, estos pueden ser analizados desde dos perspectivas: una general y una especial. La perspectiva general se desprende de la propia terminología del derecho de propiedad industrial como derecho de propiedad; a su vez, la perspectiva especial es el resultado del calificativo "industrial" de la disciplina; esta última, permite analizar ese derecho de propiedad de una forma individual y separada de cualquier otro derecho de dominio teniendo en cuenta a su vez dos situaciones: i) el objeto sobre el cual recae la protección (bienes inmateriales), y ii) la vinculación y efectos de estos derechos con el mercado.

\section{i.I. Perspectiva general de la naturaleza \\ JURÍDICA DE LA PROPIEDAD INDUSTRIAL}

La perspectiva general en el estudio de la naturaleza de la propiedad industrial impide alejarnos del postulado clásico del derecho de propiedad, el cual se determina mediante la existencia de una persona con un derecho de dominio sobre un bien que la hace titular de una serie de facultades ajustadas a una situación de poder sobre el bien que se traducen en el goce y disposición de aquel. Sin embargo, el Código Civil colombiano no ofrece una mayor descripción del derecho de propiedad sobre bienes inmateriales ya que inicialmente, en su artículo 669, acude al criterio romano del derecho de dominio sobre los bienes corporales limitando la propiedad o el derecho de dominio a las facultades de gozar y disponer de una "cosa corporal". Los artículos 653 y 671 tampoco son de gran ayuda de cara a alinear esas facultades de goce y disposición frente a bienes incorporales; aunque el artículo 653 pareciera reconocer algunos bienes incorporales termina por reducirlos a los "créditos" y a

1 Otero lastres, José Manuel. “Introducción”, en Fernández-Novoa, Carlos, Otero Lastres, José Manuel y Botana Agra, Manuel. Manual de la Propiedad Industrial, Madrid-Barcelona-Buenos Aires, Marcial Pons, 2009, p. 54.

2 Metke Méndez, Ricardo. Lecciones de Propiedad industrial, Medellín, Diké, 2006, p. 20.

3 Ídem. 
las "servidumbres activas"; por otra parte, el artículo 671 del mencionado Código reconoce la existencia de creaciones intelectuales, pero abandona las invenciones industriales sobre las que puede recaer un derecho de propiedad.

Por eso, es el artículo 670 del mismo ordenamiento el que nos permite alinear las facultades de goce y disposición con otras formas de propiedad cuando tímidamente establece que "Sobre las cosas incorporales hay también una especie de propiedad".

Teniendo en cuenta lo anterior, de alguna forma el Código Civil colombiano permite reconocer un derecho de propiedad sobre bienes incorporales que, mediante una interpretación sistemática, determinan una situación activa de dominio del titular sobre dicho bien pudiendo aquel, a su arbitrio, gozar y disponer del mencionado bien incorporal. Sin embargo, como facultades del titular sobre el bien incorporal, ese goce y disposición deben realizarse dentro de los limites de la función del derecho de propiedad so pena de estar inmerso en uso excesivo o abusivo del derecho de propiedad como se analizará más adelante.

Así las cosas, al catalogarse la propiedad industrial como un derecho de propiedad, pueden predicarse de ella las características tradicionales del derecho de dominio, entre ellas el carácter absoluto y exclusivo de cualquier derecho de propiedad. El carácter absoluto se refiere a los poderes del dueño sobre el bien "dentro de los limites impuestos por la ley y el derecho ajeno"; por su parte, el carácter de exclusivo hace referencia a la posibilidad del propietario de "oponerse a la intromisión de un tercero en ejercicio de su derecho"s, siendo el titular el único que puede gozar y disponer de su bien, salvo que haya otorgado un permiso o autorización a ese tercero.

Sin embargo, una característica propia del derecho de dominio bajo el criterio clásico romano, diferente al carácter absoluto y exclusivo, que no resalta en la propiedad industrial, por lo menos no en todos los derechos derivados de esta disciplina, es el carácter perpetuo del derecho de dominio ya que no es posible considerar que el derecho de propiedad industrial dure tanto como físicamente pueda durar el bien, ya que aquellos se conceden con una limitación temporal, salvo algunas excepciones muy especiales como en el caso de los secretos empresariales.

\section{i.2. Perspectiva especial de la naturaleza \\ JURÍDICA DE PROPIEDAD INDUSTRIAL}

La segunda perspectiva o fuente de análisis de la naturaleza jurídica de la propiedad industrial, y quizá la más importante, es aquella que se desprende del adjetivo "industrial", la cual "nos permite descubrir que los derechos de propiedad industrial son "algo más" que simples derechos de propiedad”. Esta especialidad o potencialidad del derecho de propiedad se deriva de dos presupuestos principales:

4 Velásquez Jaramillo, Luis Guillermo. Bienes, Bogotá, Temis, 2004, p. 176.

5 Ibíd., p. 177.

6 Otero lastres, José Manuel. Op. cit., p. 56. 
el primero de ellos, del objeto sobre el cual recae la protección que, a diferencia del derecho de propiedad ordinario, no recae sobre una cosa corporal o física sino sobre un bien inmaterial; el segundo presupuesto, llamativo desde cualquier punto de vista, es la vinculación de estos derechos de propiedad industrial con el mercado como consecuencia de su utilidad para fines especialmente económicos, como se mencionó; esta vinculación con el mercado es la consecuencia de la explotación económica del bien inmaterial protegido por la propiedad industrial y su relación con actividades comerciales que representan beneficios económicos.

La explotación comercial del derecho es la que hace tan especial este tipo de propiedad, ya que su titular no solamente ejerce una situación de poder sobre el bien mediante el goce y la disposición del derecho de bienes, sino que realiza una explotación del bien inmaterial para obtener una contraprestación económica, circunstancia esta que se encuentra íntimamente ligada con el segundo presupuesto que contempla la relación y el efecto de la propiedad industrial en el mercado y la competencia.

De esa manera, el análisis especial de la naturaleza jurídica de los derechos de propiedad industrial se debe hacer a partir de la palabra "industrial" que le otorga una particularidad al derecho de propiedad ordinario, la cual se define de acuerdo con: i) el objeto de protección, y ii) los efectos de tales derechos en el mercado y en la competencia, como se ilustra a continuación.

\subsubsection{El objeto de protección de los derechos de propiedad industrial}

El objeto de los derechos de propiedad industrial no tiene una "existencia sensible" por lo que pertenecen a la categoría de bienes inmateriales, los cuales son el resultado del proceso intelectual que al final se materializa en algo tangible; por tanto, no es la idea la que se protege ${ }^{8}$ sino es el resultado del esfuerzo creativo de la mente humana que, mediante los procesos adecuados, se vuelve perceptible de forma sensorial al plasmarse en soportes físicos que por su utilidad se convierten en un objeto jurídicamente protegido.

De acuerdo con Otero Lastres, la protección de la propiedad industrial se compone de una entidad inmaterial (corpus mysticum) y de una entidad material (corpus mechanicum); la primera, entendida como la creación misma, y la segunda, como aquel soporte o puente sensorial que hace perceptible la primera. En el caso de las invenciones, como las patentes y los modelos de utilidad, ostentan esa entidad inmaterial desde el momento en que solucionan el problema técnico, y la de entidad material cuando evidencian un "soporte sensible que las hace aprehensibles

7 Metke Méndez, Ricardo. Op. cit., p. 20

8 Herrera Sierra, Luisa. “¿Cuál es la adecuada extensión de los derechos de propiedad intelectual?: comentarios sobre el derecho marcario", Boletín Propiedad Intelectual, 2019. Disponible en: https://propintel.uexternado.edu.co/cual-es-la-adecuada-extension-de-los-derechosde-propiedad-intelectual-algunos-comentarios-respecto-del-derecho-marcario/, consultada el $17 \mathrm{de}$ agosto de 2020 . 
a los sentidos"; en la misma línea del diseño industrial, la creación de la apariencia es la entidad inmaterial y la entidad material es "el aspecto del producto en el que se incorpora el soporte o puente sensorial".

Ahora bien, en cuanto a las marcas, la entidad inmaterial se mantenía en el signo mismo mientras que la entidad material no tenía una concepción clara pues necesitaba materializarse a través de un soporte físico o puente sensorial. Esta ausencia de claridad cambió a partir de las marcas tridimensionales, las cuales significaron un avance del análisis tradicional del corpus mechanicum en los signos distintivos ya que en ese tipo de derechos la entidad material podía recibirse en la forma del envase mismo, o por del producto. Acá, entonces, el corpus mysticum y el corpus mechanicum son uno solo materializado en el envase, en la envoltura o en el producto propiamente dicho.

De esa forma, frente al objeto de protección de los derechos de propiedad industrial, como son las marcas tridimensionales, sobre las que haremos especial énfasis, existe una bifurcación pues, por un lado, está el signo registrado para distinguir los productos, y por otro, los productos puestos en el mercado que son la marca en sí misma; esta ambivalencia, reiteramos, cobra aún mas relevancia frente a los signos tridimensionales que representan la forma misma del producto puesto en el mercado.

\subsubsection{Efectos de los derechos de propiedad industrial en la competencia y en el mercado}

Esta segunda situación también se deriva del componente "industrial" de la disciplina, y roza con todo fundamento económico del derecho de propiedad. La convergencia misma de este enlace entre la propiedad industrial y el mercado tiene su origen en el carácter excluyente (ius prohibendi) del derecho de propiedad que analizábamos anteriormente; no obstante, como no se trata de una nota de exclusión sobre un derecho de propiedad con incursión en el mercado, esa prerrogativa implica las facultades de goce, dominio y señorío único del objeto sobre las cuales recae la protección.

En contexto, la disposición y el goce de un bien protegido mediante un derecho de propiedad industrial le otorga a su titular la oportunidad de ejercer una explotación económica de la que solo se pueda beneficiar él; desde el punto de vista del mercado, el derecho de propiedad industrial implica un círculo exclusivo de explotación sobre un bien que supone un alcance, un límite y un espacio reservado a su titular; de forma correlativa, los terceros deben abstenerse de invadir ese círculo reservado sin el consentimiento del titular. Es así como cada objeto de protección de la propiedad industrial es sustraído del "dominio público intelectual”"10: en otras

9 Otero lastres, José Manuel. Op. cit., p. 58.

10 Landes, William M. y Posner, Richard A. The Economic Structure of Intellectual Property Law, Sánchez Álvarez, Victor Manuel (trad.), Madrid, Fundación Cultural del Notario, 2006, p. 23. 
palabras, es una nube de ideas y creaciones flotantes que no están protegidas pero que en caso de estarlo son extraídas del principio de libre competencia económica y libre empresa ${ }^{11}$. Landes y Posner ${ }^{12}$ trabajan este concepto mediante la ejemplificación del movimiento de cercado de campos en Inglaterra que transformó los pastizales comunes en propiedad privada, donde el propietario del campo cercado podía prohibir el uso de su pastizal para el pastoreo del ganado de su vecino, prohibición que al ser avalada por la ley debía ser respetada por los jueces.

De esa forma, gracias a la exclusividad y a la exclusión, el derecho de propiedad industrial representa un bloqueo que le permite al titular excluir a todos los demás del objeto sobre el que recae su derecho y, al tratarse de derechos industriales, puede retirar y oponerse a todo aquel que haga uso del objeto de protección que está siendo introducido en el mercado, determinando así los efectos sobre el mercado y la competencia.

Teniendo en cuenta lo anterior, gracias a su atributo industrial, los derechos de propiedad industrial tienen una naturaleza jurídica que trasciende el puro derecho de propiedad clásico, debido a que, si bien recogen los elementos tradicionales del derecho de propiedad, tienen unas características singulares y excepcionales.

\section{VINCULACIÓN DE LA PROPIEDAD INDUSTRIAL Y EL MERCADO, Y SU POSIBLE ALTERACIÓN MEDIANTE MARCAS CONSTITUIDAS}

\section{POR LA FORMA DE LOS PRODUCTOS}

Las formas del producto son usualmente protegidas mediante marcas tridimensionales las cuales, como ya lo mencionamos, tienen una bifurcación en el objeto de protección, ya que por un lado está el signo registrado para distinguir los productos, y por otro los productos puestos en el mercado que son la marca en sí misma. De esta manera, las marcas tridimensionales que representan la forma del producto tal y como es puesto en el comercio deben incorporar, en todo caso, dos elementos fundamentales para determinar su existencia, uno de ellos es el "elemento central del derecho de marcas consistente en la capacidad distintiva del signo"13 y el otro, es la susceptibilidad de representación gráfica.

En principio, el carácter distintivo está alineado con una de las finalidades básicas de la marca, consistente en indicar el origen empresarial del producto y poder

11 Otero lastres, José Manuel. Op. cit., p. 59.

12 Landes, William M. y Posner, Richard. Op. cit., pp. 22-23. "Si A es propietario de un pastizal, dispondrá de la facultad de prohibir a terceros que lleven allí a pastar su ganado con el respaldo de los tribunales y las fuerzas del orden. A no tiene que negociar un acuerdo con terceros en virtud del cual se reserva un derecho de exclusividad en el uso del pastizal; ésta sería una alternativa inviable, pues los terceros podrían amenazar con llevar su ganado a pastar al pastizal con la finalidad de que A les pague por no hacerlo. En cambio, si B desea usar en exclusiva el pastizal, debe adquirirlo en unos términos aceptables para A. Así pues, un derecho de propiedad comprende tanto la facultad de excluir a terceros como la de transmitir el bien a un tercero".

13 Guerrero Gaitán, Manuel. "Las marcas no tradicionales. Inconvenientes prácticos y aceptación en el derecho comparado”, en Guerrero Gaitán, Manuel, Payán Rodríguez Carlos felipe y Velazco Ordóñez, Pablo. Op. cit., p. 100. 
diferenciarlo de los bienes de otros empresarios ${ }^{14}$. Por su parte, la representación gráfica, en cualquiera de sus novedosas variables, es el resultado del dinamismo en el tráfico económico y del alcance de la creatividad humana, dos componentes que obligan a explorar nuevas alternativas de representación; es por ello que diferentes regímenes, entre los que se encuentra el de la Comunidad Andina, entregaron una lista de posibilidades para que los signos distintivos puedan ser representados; así, en el literal f del artículo 134 de la Decisión 486 de 2000 se ubican las formas de los productos, envases y envolturas como posibilidades de conformar marcas. Como se observa, no solo se establece la posibilidad de registrar como marca los embalajes y envases de los productos sino los productos propiamente dichos, los cuales deben estar dotados de una altura, de un ancho y de una profundidad representadas de una manera que permita visualizarse.

Sin duda la forma del envase o embalaje del producto es una de las representaciones más comunes en ese tipo de marcas. Es usual observar la protección de la forma de envoltorios, envases, botellas y otras formas de exposición o portabilidad de los productos, lo cual obedece a que, en razón a su naturaleza, la representación del producto puede carecer de una forma definida por sí misma (agua, gaseosas, líquidos), por lo que requiere de un empaque o envase para su comercialización ${ }^{15}$.

Algunos ejemplos de marcas (envase o embalaje del producto) registradas en Colombia pueden ser los siguientes (imágenes tomadas del Sistema de Propiedad Industrial de la Superintendencia de Industria y Comercio):

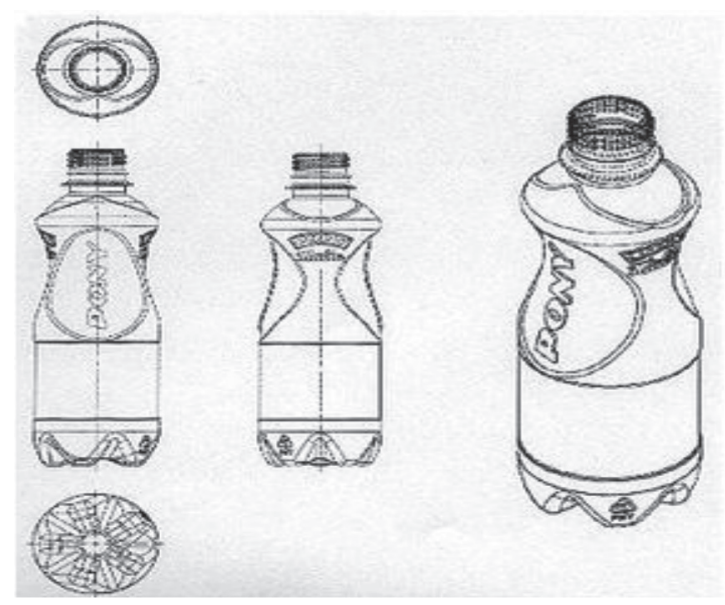

Registro n. ${ }^{\circ} 380831$, Clase 32

14 Rey-Alvite Villar, Manuel. "El carácter distintivo de la marca tridimensional en la jurisprudencia de la Unión Europea”, Cuadernos de Derecho Transnacional, vol. 6, n. ${ }^{\circ}$ 1, p. 306: "El carácter distintivo de una marca es la aptitud de esta para identificar los bienes o servicios que designa con un determinado origen empresarial, distinguiéndolos de otros bienes o servicios similares presentes en el mercado. Se trata de un rasgo esencial no sólo para la marca, sino para cualquier signo distintivo, del que éstos adquieren su misma denominación".

15 Ibíd., p. 300. 


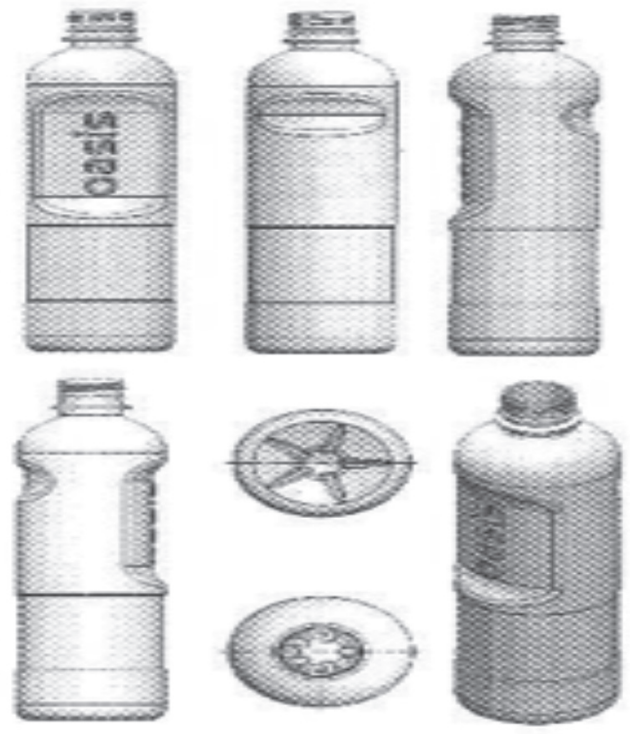

Registro n. ${ }^{\circ} 388346$, Clase 32

Por otro lado, la norma comunitaria prevé expresamente como objeto de protección la forma del producto en sí misma, y es ahí cuando aparece claramente la bifurcación del objeto de protección del derecho de propiedad industrial que mencionábamos anteriormente, pues coinciden en uno solo el signo distintivo (marca) y el producto. Algunos ejemplos de aquellas marcas constituidas por la forma del producto registradas en Colombia pueden ser los siguientes (imágenes tomadas del Sistema de Propiedad Industrial de la Superintendencia de Industria y Comercio):

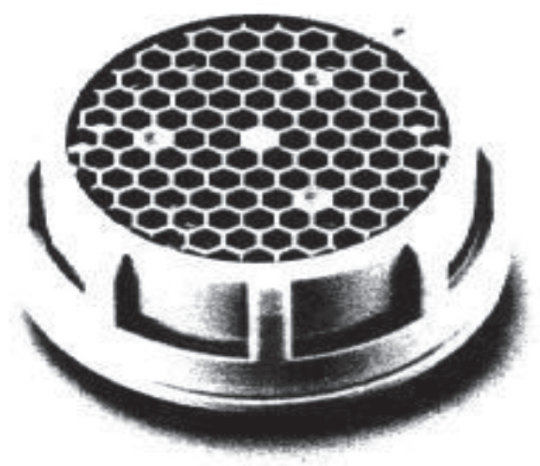

Registro n.o 269337, Clase $11^{[16]}$

16 El registro n. ${ }^{\circ} 269337$ se trata de una forma producto denominado "aireador" usado como filtro limpiador de agua potable. 


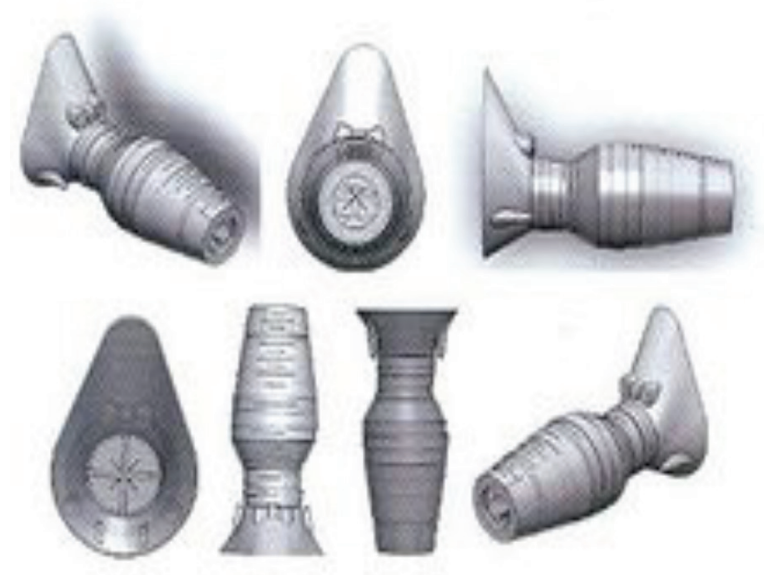

Registro n. ${ }^{\circ}$ 465561, Clase 10

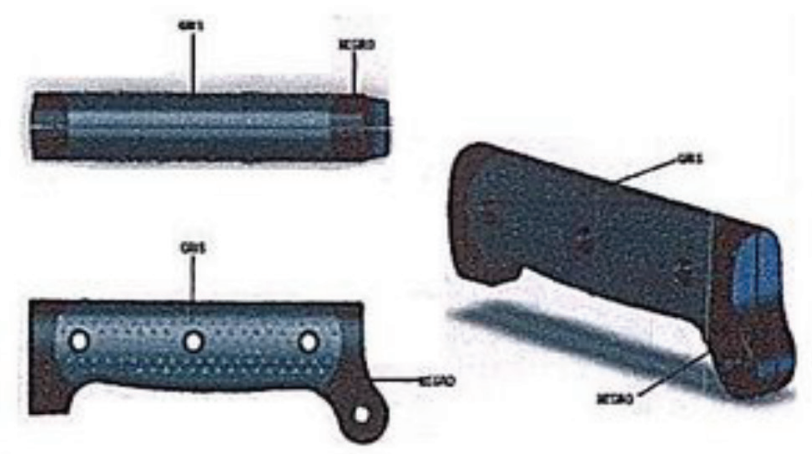

Registro n. ${ }^{\circ} 476426$, Clase $8^{[17]}$

Este objeto de protección sobre las formas de productos ha tenido grandes debates en el escenario local e internacional, ya que al accederse al registro de marca que representa la forma misma del producto, se genera una colisión con el objeto de protección de otro tipo de derechos de propiedad industrial como el diseño y en algunos casos con la patente de invención. De la misma forma, este debate alcanza un nivel elevado de análisis por los resultados en la competencia y en el mercado ante un derecho exclusivo con una protección renovable en el tiempo de forma indefinida sobre la estructura externa del producto, especialmente, cuando aquel es único en la industria.

17 El registro n.o 476426 pertenece a una compañía dedicada a la fabricación de artículos de cuchillería, herramientas de mano y artículos de ferretería. 
Así las cosas, en esta tipología marcaria el soporte sensible de la marca es ella misma, por lo que, mediante esa forma de signo distintivo es posible percibir con los sentidos, principalmente el tacto y la vista, la marca en sí misma. El Tribunal de Justicia de la Comunidad Andina ha definido las marcas tridimensionales como "[...] aquellas que poseen volumen y que ocupan por sí mismas un espacio determinado, conforme lo explica el propio término tridimensional, que da la idea de la ocupación de las tres dimensiones del espacio (alto, ancho y profundidad)"18; de igual forma, el mismo Tribunal expresó que "[...] la marca tridimensional se la define como un cuerpo que ocupa las tres dimensiones del espacio y que es perceptible no sólo por el sentido de la vista sino por el del tacto"19.

De esa manera, conforme a las interpretaciones del Tribunal de Justicia de la Comunidad Andina, las marcas que representan la envoltura del producto, o el producto en sí mismo, tienen la posibilidad, o quizá la obligatoriedad, de ser perceptibles a los sentidos del ser humano, en especial al sentido del tacto, el cual implica sentir el producto, rozarlo y tener contacto físico con él, que a la vez es la marca; en ese orden de ideas, se puede concluir que aquellas marcas tienen una materialización física en el mundo de lo tangible.

Es importante detenernos aquí en los conceptos de percepción y representación, siendo el primero aquel proceso que le permite a una persona (usualmente el consumidor) recibir, elaborar e interpretar a través de los sentidos la información proveniente de un objeto: "la percepción implica una aprehensión profunda de la realidad capturada por los sentidos" 20 , en este caso, la vista, el olfato, el tacto, el oído y el gusto. Para la representación se debe utilizar un modo que le permita a cualquier persona consultar las características del signo (dimensiones) para comprender su sentido, su naturaleza y el alcance de su protección, características que se plasmarían en el certificado de registro; sin embargo, hay se debe tener en cuenta que dicho certificado no puede ser entendido como el objeto de protección y mucho menos como el soporte material o el puente sensorial pues, como ya lo dijimos, ese soporte sensorial es el envase o el producto en sí mismo.

Esta discusión incrementa el debate al intentar adecuar las marcas tridimensionales como bienes inmateriales, ya que el hecho de requerir un envase o un producto físico como representación gráfica, cambia su interpretación original de marcas como bienes intangibles a bienes corporales o tangibles ${ }^{21}$.

18 Comunidad Andina. Tribunal de Justicia de la Comunidad Andina, Proceso 31 IP-2003, Gaceta Oficial del Acuerdo de Cartagena n.o 960 del 1. ${ }^{\circ}$ de agosto de 2003.

19 Comunidad Andina. Tribunal de Justicia de la Comunidad Andina, Proceso $153-$ IP-2005, Gaceta Oficial del Acuerdo de Cartagena n.o 1284 del 13 de enero de 2006. Actor: Parke, Davis \& Co. Limited. Marca: "Halitos"; y Proceso 33-IP-2005 en Gaceta Oficial del Acuerdo de Cartagena n. ${ }^{\circ} 1284$ del 2 de agosto de 2005. Actor: Bavaria S.A. Marca: "Forma de Botella".

20 Castro García, Juan David. "Las marcas no tradicionales”, Revista La Propiedad Inmaterial, n. ${ }^{\circ}$ 16, 2012, p. 298. Disponible en [https://revistas.uexternado.edu.co/index.php/ propin/article/view/3273/2922].

21 Fernández-Novoa, Carlos. Tratado sobre Derecho de Marcas, 2.a ed., MadridBarcelona, 2004, p. 27 y ss. 
Con base en lo mencionado, el ejercicio del derecho a competir y la libertad económica se pueden ver restringidos, eliminados o alterados de diversas maneras, entre ellas, mediante el reconocimiento de derechos de propiedad industrial a signos relacionados con las marcas; esta alteración de la competencia ha sido reconocida o considerada como legítima ya que está contemplada y reglamentada por normas de carácter constitucional y legal que protegen bienes jurídicos como los derechos inmateriales derivados de aquella disciplina ${ }^{22}$. Al respecto, la misma doctrina autorizada considera que aquellos derechos de propiedad industrial, "dentro de la escala de valores de nuestro ordenamiento jurídico se prefieren en ciertas instancias al derecho a la libre competencia económica" ${ }^{23}$; al respecto pareciera que, dentro de una disputa por la búsqueda del balance de derechos, el derecho de la competencia se rinde de cierta manera frente a la propiedad industrial.

Tratándose de marcas, la vinculación del mercado, la competencia y la propiedad industrial son resultado de la dimensión positiva del derecho exclusivo que se ejerce sobre ellas, dimensión que implica que el titular de la marca dispone en exclusiva de tres facultades esenciales: i) la de aplicar la marca en el producto; ii) la de poner en el comercio o introducir en el mercado los productos identificados mediante la marca, y iii) la de emplear la marca en la publicidad ${ }^{24}$. Claramente las actividades que se desprenden de esas tres facultades son el camino que conecta la propiedad industrial sobre las marcas con el mercado, conexión que predomina respecto de la segunda facultad ya que es mediante el uso de la marca que su titular puede conseguir varios objetivos de cara a sus competidores.

Teniendo en cuenta lo anterior, los derechos de propiedad industrial son elementos de un sistema económico ${ }^{25}$ que otorgan ventaja competitiva legítima y autorizada por el ordenamiento nacional y comunitario. Sin embargo, como derechos de propiedad industrial, las marcas son consideradas jurídicamente como monopolios debido a las características de exclusividad y exclusión mencionadas, en razón a que el ejercicio de señorío y dominio sobre ellas restringe la competencia sobre los bienes en los que recae la protección industrial. Es importante comprender que el monopolio conformado o estructurado inicialmente por los derechos de propiedad industrial no constituye el monopolio de tipo económico usualmente conocido donde la producción de un bien se concentra únicamente en un agente; el monopolio al que se refieren los derechos de propiedad industrial es

22 Miranda Londoño, Alfonso. "El Régimen General de la Libre Competencia. Características principales", en Segundo Congreso Iberoamericano de Derecho Empresarial. Formas de control, colaboración, competencia empresarial y propiedad industrial, Bogotá, octubre de 1997, p. 3. Disponible en [https://centrocedec.files.wordpress.com/2010/06/el-regimengeneral-de-la-libre-competencia-alfonso-miranda-londono.pdf].

23 Ídem.

24 Fernández-Novoa, Carlos. "Posición jurídica del titular de la marca”, en Fernández-Novoa, Carlos, Otero lastres, José Manuel y Botana Agra, Manuel. Op. cit., pp. 582-585.

25 Rengifo García, Ernesto. Del abuso del derecho al abuso de la posición dominante, 2. a ed., Bogotá, Universidad Externado de Colombia, 2004, p. 431. 
de tipo legal y hace alusión a esa exclusividad derivada del derecho de propiedad clásico que vimos al principio.

No obstante, tratándose de marcas constituidas por la forma del producto, ese monopolio legal podría derivar en un monopolio de tipo económico. En ese caso cambiaría la percepción de aceptación derivada del derecho de la competencia frente a los monopolios autorizados que derivan de la propiedad industrial ya que habría una restricción en el acceso a otros participantes sobre un producto con determinada forma, y la oferta de ese producto se concentraría en un solo agente. En otras palabras, si la forma del producto protegida mediante la marca hace parte de una amplia oferta de formas no creará una restricción relevante de competencia que pueda derivar en un monopolio económico; por el contrario, si la forma del producto protegida mediante la marca hace parte de un mercado estrecho donde la única forma del producto es aquella protegida por el derecho de propiedad industrial, se podría estructurar una estricta barrera de entrada de otros productos con formas similares al mercado.

Como lo hemos visto, las marcas tridimensionales que representan la forma de los productos son una especie particular que las separa de las marcas tradicionales, especialmente de las denominativas y las figurativas, ya que la marca tridimensional enlaza en uno solo el signo objeto de protección como bien inmaterial y el medio (producto) en el que se plasma ${ }^{26}$. Sin embargo, cuando ese producto protegido mediante el signo tridimensional es el único que se encuentra disponible en el mercado, el efecto de limitación de la competencia es irresistible, siempre que no haya sustitutos de aquel producto dentro del mercado relevante. De esa manera, la concesión de un derecho de propiedad industrial que cobije la forma del producto restringe la competencia en mayor medida de lo necesario con el fin de asegurar los beneficios de los derechos de propiedad ${ }^{27}$.

A pesar de lo anterior, si bien el literal f del artículo 134 de la Decisión 486 de 2000 permite el registro como marca de "la forma de los productos, sus envases o envolturas", existe una causal de irregistrabilidad prevista en el literal c del artículo 135 de la norma comunitaria, tendiente a impedir el registro de formas de productos consideradas como usuales, más no el registro de formas de productos sin sustitutos.

De esta manera, la causal contenida en el literal c del artículo 135 de la Decisión 486 de 2000 sirve para aplacar la concesión de un derecho de propiedad industrial y sus consecuentes efectos sobre el mercado cuando aquel comprende una forma de producto usual, pero no permite eliminar la posibilidad de registro y sus consecuencias para la competencia de un derecho de propiedad industrial que proteja una forma de producto singular sin sustitutos en el mercado, es decir, sobre una forma de un producto que no tenga otro que lo reemplace funcionalmente.

27 Landes, William M. y Posner, Richard. Op. cit., p. 486. 
Por eso, una vez el titular ha adquirido el derecho de propiedad sobre la forma del producto para ejercer sus derechos de señorío mediante el uso y explotación económica única y excluyente sobre él sin sustitutos perfectos (monopolio legal), surge una situación monopolística de tipo económico (monopolio económico) en la cual el agente titular del derecho de propiedad industrial es el único facultado legítimamente para poner en el comercio dicho producto, teniendo así, no solo el monopolio exclusivo sobre el producto sino un poder de mercado o posición dominante, ya que rompe la igualdad económica con los demás agentes porque los consumidores no podrán reemplazar aquel producto por otro que satisfaga la misma necesidad pues no estará disponible en el mercado, y de estarlo, sería un producto infractor comercializado en la ilicitud.

El derecho de propiedad sobre una forma de producto sin sustitutos llevaría a que a otros agentes les sea imposible ingresar al mercado de aquel producto y provoque que su titular enfrente solo toda la demanda del mercado, de esta manera será él quien decida qué cantidad de bienes producir y su voluntad será la que determine el precio ${ }^{28}$. Así, la limitación total de la competencia derivada de un monopolio legal, como es el derecho de propiedad sobre la forma de producto, no solo lleva a un monopolio de tipo económico sino a un gran poder de mercado que coincide con los elementos de la posición de dominio dentro de la óptica del derecho económico.

\section{I. POSICIÓN DE DOMINIO DERIVADA DE UN DERECHO DE PROPIEDAD INDUSTRIAL CONFORMADO POR LA FORMA DE UN PRODUCTO}

En Colombia la posición de dominio se encuentra definida por el numeral 5 del artículo 45 del Decreto 2153 de 1992 como "[l] a posibilidad de determinar, directa o indirectamente, las condiciones de un mercado". De igual forma, la posición de dominio se presenta cuando "un agente del mercado puede comportarse con independencia de competidores, clientes y consumidores, de manera que puede imponer unilateralmente las condiciones del mercado sin que tal situación pueda ser efectivamente contrarrestada por los demás agentes" 29 .

Frente a la posición de dominio, la Superintendencia de Industria y Comercio ha señalado:

[P]ara determinar la posición de dominio en un mercado relevante se debe analizar, en esencia, la estructura de competencia en el mercado, lo cual incluye un análisis

28 Velandia, Mauricio. Derecho de la competencia y del consumo. Competencia desleal; abuso de la posición de dominio; carteles restrictivos; actos restrictivos; integraciones económicas y protección al consumidor, 2. ${ }^{a}$ ed., Bogotá, Universidad Externado de Colombia, 2011 , p. 33.

29 Arboleda Suárez, Carlos Ignacio. "El abuso de la posición de dominio en Colombia", Revista de Derecho de la Competencia, Centro de Estudios de Derecho de la Competencia (Cedec), vol. 13, n. ${ }^{\circ}$ 13, Bogotá, Pontifica Universidad Javeriana, p. 113. 
de cuotas de mercado y niveles de concentración, las características de la demanda, los competidores, la existencia de barreras a la entrada, así como otros factores que le permitan a la empresa actuar de manera independiente en el mercado. En concreto, lo que se quiere determinar al analizar si una empresa tiene posición dominante es si dicho ente económico tiene la capacidad para establecer, de forma unilateral, las condiciones de un mercado ${ }^{30}$.

Adicionalmente, la Superintendencia de Industria y Comercio sostiene que

Para determinar la posición de dominio en un mercado relevante se debe analizar, en esencia, la estructura de competencia en el mercado, lo cual incluye un análisis de cuotas de mercado y niveles de concentración, las características de la demanda, los competidores, la existencia de barreras a la entrada, así como otros factores que le permitan a la empresa actuar de manera independiente en el mercado ${ }^{31}$.

Así las cosas, para saber si un agente tiene o no posición de dominio y si cuenta con la independencia para actuar en el mercado, es preciso analizar el nivel de sustitución del producto y el número de empresas que fabrican aquellos bienes sustitutos. Ahora bien, para definir la sustituibilidad de un producto se debe tener "en cuenta que los sustitutos satisfagan las necesidades que el consumidor pensaba cubrir con la adquisición del bien principal”32, máxime respecto de su función, para luego concentrarse en el precio, en la calidad y en su duración.

En consecuencia, al analizar si una empresa tiene posición dominante se determina su capacidad para establecer de forma unilateral las condiciones de un mercado, situación que, respecto de un agente que adquiere un derecho sobre la forma de un producto sin sustitutos, generaría una clara posición de dominio debido a la capacidad para excluir a otras empresas competidoras del uso de una forma similar o idéntica a la protegida. De lo anterior, es evidente que "si un mercado no tiene sustitutos será dependiente de un agente económico"33, que corresponde al supuesto bajo estudio. Así las cosas, el agente económico tendría un refuerzo en su posición de dominio originada y respaldada en un derecho de propiedad industrial.

De esa manera, la posición de dominio derivada de la adquisición de un derecho de propiedad industrial sobre una forma sin sustitutos que se relaciona con el mercado, le permite al titular del derecho de propiedad actuar de forma independiente respecto de sus competidores, e incluso frente a los consumidores sin las implicaciones propias de la demanda y sin tener en cuenta, por supuesto, los demás agentes económicos. El mercado dependerá en gran medida del titular 
único de la forma de producto por la estrechez de la oferta, quien, al no contar con competencia, decidirá sobre las condiciones del mercado de aquel bien.

Esta situación se relaciona con la elasticidad de la demanda, siendo esta elástica cuando en aquel mercado existen sustitutos para un producto que satisfacen la necesidad del consumidor ${ }^{34}$, pero en el caso evaluado, además de no existir sustitutos del producto, su forma está protegida mediante derechos de propiedad derivados de una marca tridimensional, así las cosas, el mercado dependerá de un solo agente económico, el titular de la marca. No obstante, en un análisis de los derechos de propiedad industrial es usual que se verifique la posibilidad de generar copias no autorizadas del mismo por terceros agentes sin autorización de su titular, infracción que podría ser generadora de sustitutos del producto, y estar encausada en una ilicitud que atenta contra el derecho de propiedad industrial y que faculta a su titular para perseguir al agente infractor y prohibirle, mediante el ius probibendi, la creación y comercialización de la forma de producto protegida.

La posición de dominio no está prohibida per se, y mucho menos cuando ha sido consolidada mediante la adquisición de derechos de propiedad industrial que la legitiman, por lo que no es ilegal ni reprochable, aunque sí su abuso, tal y como lo sostiene el artículo 333 de la Constitución Política colombiana al manifestar que "[e]l Estado, por mandato de la Ley, impedirá que se obstruya o se restrinja la libertad económica y evitará o controlará cualquier abuso que personas o empresas hagan de su posición dominante en el mercado nacional". De esa forma, es claro que se admite la posición de dominio en una economía de mercado, pero se proscribe su abuso.

$\mathrm{Al}$ respecto, la Superintendencia de Industria y Comercio ha establecido que la situación de poder que se desprende de la posición de dominio en un agente del mercado le implica un régimen de responsabilidad especial debido a la influencia que tiene sobre el mercado, esta situación supone un deber de cuidado en su conducta superior al exigido a sujetos que se encuentran en una competencia sin distorsiones, como aquella en la que no hay presencia de un agente dominante ${ }^{35}$.

Así las cosas, solo queda preguntarnos si se considera entonces un abuso de la posición de dominio tomar ventaja en el mercado mediante la conformación de derechos de propiedad sobre formas de productos sin sustitutos.

La respuesta a este interrogante es que es necesario que el modelo de conducta propuesto infrinja alguna prohibición del artículo 50 del Decreto 2153 de 1992; del mismo modo, se exige que la conducta no esté destinada de ninguna manera a crear efectos pro-competitivos, tampoco a producir mejoras en eficiencias ni a procurar beneficios a los consumidores suficientes para compensar los efectos anticompetitivos derivados del abuso de la posición del dominio. Ahora bien, el artículo 50 enlista las conductas constitutivas de abuso de posición de dominio, las cuales son divididas en dos categorías, la primera de ellas trata de los abusos

35 Colombia. Superintendencia de Industria y Comercio. Resolución 53403 de 2013. 
relacionados con la explotación y la segunda, con los abusos relacionados con la exclusión:

Los abusos de explotación son aquellos en que la empresa dominante aprovecha su poder de mercado para directamente apropiarse de parte de la renta de sus clientes, mediante acciones tales como el aumento de los precios, la reducción de la calidad o la variedad de los productos, o la discriminación de clientes no basada en criterios objetivos.

Por su parte, los abusos de exclusión son aquellos en los que la empresa dominante directamente limita la competencia mediante conductas que obligan a los competidores a abandonar el mercado, a impedir u obstruir su acceso o los fuerzan a ejercer una competencia débil o a no expandirse ${ }^{36}$.

Si bien está en discusión la limitación taxativa del artículo 50 del Decreto 2153 de 1992 sobre las conductas que son consideradas como abuso de la posición de dominio ${ }^{37}$, lo cierto es que la conducta concreta relacionada con apropiación legítima de una forma de producto mediante un derecho de propiedad industrial (marca tridimensional), no encaja en ninguna de las seis conductas previstas en el artículo 50 del Decreto 2153 de 1992; por lo pronto, no podríamos estar frente a un abuso de posición de dominio cuando el titular de la forma del producto sin sustitutos ejerce sus prerrogativas de exclusión frente aquellos que pretenden imitar la forma del producto protegida.

Lo anterior es posible confirmarlo de la siguiente forma: la hipótesis prevista en el numeral 1 (precios predatorios) del artículo 50 del Decreto 2153 de 1992 está íntimamente ligada con la definición del precio del producto de acuerdo con la estructura de costos del agente; las conductas de los numerales 2 y 4 (discriminación) están relacionadas con el tratamiento diferenciado del sujeto dominante del mercado cuando discrimina consumidores en situaciones análogas, o cuando su intención es eliminar la competencia; el numeral 3 (ventas atadas) se materializa cuando el agente que ejerce dominio se aprovecha para subordinar la venta de un producto a otro; y el numeral 5 (discriminación geográfica de precios) está relacionado con la definición de precios bajos en determinado lugar con el fin de eliminar la competencia. Estas situaciones no están relacionadas con la apropiación

36 Ibíd., p. 116.

37 Ibíd., p. 117. Resolución 53403 de 2013. "La finalidad de la norma prevista en el artículo 50 del decreto 2153 de 1992 no es definir de manera exhaustiva qué debe entenderse por abuso de posición de dominio, sino que se circunscribe a establecer un listado indicativo de conductas que, de posición de dominio, sino que se circunscribe a establecer un listado indicativo de conductas que, de ser comprobadas, serían restrictivas de la libre competencia como ejercicio indebido de la posición dominante conductas constitutivas de abuso por agentes que ostenten poder de mercado, es precisamente en este escenario en el que cobra particular relevancia la prohibición general de la que trata el artículo $1 .^{\circ}$ de la Ley 155 de 1959”. 
legítima de una forma de producto mediante un derecho de propiedad industrial (marca tridimensional).

Sin embargo, el numeral 6 (obstrucción de acceso al mercado para terceros) del artículo 50 del Decreto 2153 de 1992, al ser una conducta más general, pareciera dar espacio para entender que la apropiación de una forma de producto sin sustitutos mediante derechos de propiedad industrial sea un abuso de la posición de dominio por parte del titular del derecho ya que este, al ejercer su facultad negativa de exclusión o ius prohibendi, pretende "[...] impedir a terceros, el acceso a los mercados o a los canales de comercialización" donde se encuentre su producto protegido mediante una forma tridimensional.

No obstante, la Superintendencia de Industria y Comercio ha determinado que obstruir o impedir la entrada de terceros a un mercado no es una conducta ilegal por sí misma, sino que requiere la demostración efectiva de la obstrucción o de la forma como se impidió la entrada a un mercado determinado o a los canales de comercialización, o que aquella resultó necesaria ${ }^{38}$. Por demás, es importante tener en cuenta que la obstrucción o el impedimento de acceso al mercado para otros agentes es legítimo gracias a la facultad negativa de exclusión que cobija al titular de un derecho de propiedad industrial, por tanto, dicha obstrucción no podría ser catalogada como un abuso de la posición de dominio.

\subsection{LA COMPETENCIA DESLEAL FRENTE A UN DERECHO}

DE PROPIEDAD INDUSTRIAL CONFORMADO POR LA FORMA DE UN PRODUCTO

Como vimos, las marcas pueden llegar a tener como objeto de protección las formas de productos (sin sustitutos) que necesariamente sean implementados dentro de una actividad realizada en el mercado y que resultaría idónea -para el titularno solo para mantener su participación en el mercado, sino para incrementarla. Con ello, se estarían cumpliendo las condiciones de aplicación para que dicha apropiación pudiese ser considerada como desleal ${ }^{39}$. Por ende, si en la situación descrita se confirma una desventaja o un perjuicio en contra de un competidor, se puede explorar la viabilidad de iniciar las acciones previstas en la Ley 256 de 1996 y encajar la situación descrita en alguna de las conductas contempladas en dicha ley, con el fin de prevenir, eliminar y restaurar los daños derivados del acto considerado como desleal.

En el anterior panorama es importante tener en cuenta que la acción de competencia desleal puede ser promovida como defensa de un competidor frente a la apropiación de la forma de productos sin sustitutos, sea como accionante directo o mediante una demanda de reconvención en un proceso iniciado por el titular del derecho de propiedad industrial. Sin embargo, ya sea por una acción directa, o a

38 Colombia. Superintendencia de Industria y Comercio. Resolución 40912 de 2012.

39 De la Cruz, Dionisio. La competencia desleal en Colombia. Un estudio sustantivo de la ley, 2. ${ }^{a}$ ed., Bogotá, Universidad Externado de Colombia, 2020, p. 21-37. 
través de una demanda de reconvención, es imposible limitar el alcance del derecho constituido mediante un acto emanado del Estado, ya que si de discutir el derecho se trata, por su carácter civil (sustancial y procesal), la acción de competencia desleal no puede restarle eficacia a la resolución de concesión del derecho sobre la forma de producto, pues el juez de conocimiento está limitado en sus facultades para afectar el acto administrativo de concesión ${ }^{40}$.

En algún momento se exploraron llamativas modificaciones para los procedimientos relacionados con la infracción a derechos de propiedad industrial donde se pudiese alegar, como excepción para enervar las pretensiones, la nulidad del derecho de propiedad industrial que pudiera ser declarada por el juez (civil) que conociera la acción de infracción, únicamente con efectos para el caso que se estuviera debatiendo ${ }^{41}$. Hubiese sido interesante que dicha posibilidad se hubiera estudiado no solo para procesos de infracción de derechos de propiedad industrial, sino también para asuntos de competencia desleal vinculados con propiedad industrial.

Ahora bien, aunque dicha modificación normativa nunca se dio, es claro que existe la necesidad de habilitar escenarios jurisdiccionales de carácter civil en los que se pueda discutir la eficacia y validez de los actos que conceden derechos de propiedad industrial al interior de procesos de infracción o incluso de competencia desleal. Tal reforma hubiera contemplado una herramienta jurisdiccional para prevenir consecuencias adversas derivadas del uso exclusivo sobre derechos de propiedad industrial conformados por una forma de productos sin sustitutos. Así las cosas, a la fecha de elaboración de este artículo, no existe la posibilidad antes mencionada, ya que mientras el acto administrativo que concede el signo se encuentre en firme y vigente, la eventual acción de competencia desleal no mitiga los efectos derivados de la explotación del derecho industrial en la competencia.

\subsection{Entre el "Uso abusivo" y el "Uso exCesivo" de los derechos de PROPIEDAD INDUSTRIAL CONFORMADOS POR LA FORMA DE UN PRODUCTO}

En ese orden de ideas, si el monopolio económico, o la eventual deslealtad que se deriva de la apropiación de una forma que representa un producto único en el

40 Colombia. Superintendencia de Industria y Comercio. Delegatura para Asuntos Jurisdiccionales, Sentencia del 21 de febrero de 2019, Acción de infracción a derechos de propiedad industrial de Crocs Inc. contra Evacol S.A.S., Expediente 16-230917. Disponible en [https://vimeo.com/319956763].

41 Colombia. Congreso de la República. Proyecto de Ley n.o 38 de 2015, "por medio del cual se introducen modificaciones al régimen de protección de la competencia, a las funciones de la Superintendencia de Industria y Comercio, y se dictan otras disposiciones [...] Artículo 21. Excepción de nulidad en procesos de infracción de derechos de propiedad industrial. En la acción por infracción de derechos de propiedad industrial el demandado podrá proponer como excepción de mérito la nulidad del derecho de propiedad industrial que se pretende proteger, la cual podrá ser declarada por la autoridad que esté conociendo de la acción por infracción. La eventual declaración de dicha nulidad del derecho de propiedad industrial por vía de excepción de mérito sólo tendrá efectos en el caso concreto". 
mercado mediante el cual se obstruye, limita e impide el ingreso de agentes a un mercado, no puede ser considerado como un abuso de la posición de dominio ni atacado por acciones de competencia desleal, dicha conducta está más alineada con un abuso o un uso excesivo del derecho de propiedad industrial desde el punto de vista del derecho clásico de propiedad, situaciones que se analizarán a continuación.

El abuso del derecho se presenta como un principio general del derecho positivo y claramente como conformador de la apertura de fuentes del derecho; es una institución clásica del derecho civilista y ostenta una cercanía con el derecho de propiedad de donde se desprende su origen. A su turno, inicialmente el derecho de propiedad se analizaba desde el derecho de dominio sobre bienes inmuebles destinados históricamente a la habitación y residencia de personas y para actividades industriales y comerciales. Al estar esos bienes agrupados en centros urbanos, los inmuebles se situaban uno al lado del otro y de allí se desprendían las obligaciones de vecindad.

Aquellas obligaciones de vecindad constituían un estándar de calificación de la conducta de los actos que los propietarios de inmuebles realizaban sobre sus bienes cuando estos pudiesen ocasionar daños a los bienes de sus vecinos. De esa manera, la verificación de los actos de señorío sobre un bien partía del estudio de su necesidad dentro del desarrollo de las actividades que se realizaban al interior del inmueble, por tanto, las actividades realizadas dentro de inmuebles destinados a vivienda eran calificadas de forma diferente que aquellas realizadas en inmuebles con destinación industrial o comercial.

Actualmente la verificación de los actos sobre la propiedad se realiza mediante la denominada relatividad de los derechos subjetivos, que implica revisar la intención, la utilidad y la legitimidad con que se realiza determinado acto en el ejercicio del derecho de propiedad con el fin de detectar si se acompasa o no con la finalidad del derecho subjetivo. Sin embargo, dicho ejercicio de verificación se activa solo cuando un determinado acto ocasiona un daño en la propiedad ajena o cuando se está ante un riesgo inminente de daño frente a los bienes del vecino, los cuales también están cobijados por el derecho de propiedad.

Así las cosas, el primer análisis se centra en el motivo o la intención del acto a fin de conocer si hubo o no un abuso del derecho. En ese estándar de valoración se identifica si el móvil del actor se concretó en un hecho doloso o de mala fe, y si la conducta se orientó de acuerdo con la finalidad del derecho ${ }^{42}$. De esa forma, "no se toma en consideración únicamente la intención, sino que también la dirección de la conducta en comparación con la dirección querida socialmente de acuerdo con el contenido del derecho ejercido" ${ }^{\$ 3}$. Frente al presupuesto volitivo, Leonfanti

42 Ortiz Justiniano, Catalina. "La intencionalidad en el concepto de abuso en el derecho privado y en libre competencia”, Memoria de prueba para optar al grado de licenciado en ciencias jurídicas y sociales, Santiago de Chile, Universidad de Chile, p. 36.

43 Josserand, Louis. De l'esprit des droits et de leur relativite, Paris, Librairie Dalloz, 1927, p. 13, citado por Ortiz Justiniano, Catalina. Op. cit., pp. 37-38. 
explica que un acto "[...] implica abuso siempre que el ejercicio del derecho de propiedad se realiza con un fin ilegítimo, vale decir con la intención de dañar y sin utilidad sería y legítima, fórmula admitida por a jurisprudencia” ${ }^{34}$.

De esa manera, no cualquier acto derivado del ejercicio del derecho de propiedad puede ser catalogado como abusivo, sino que ese abuso deviene solo cuando el acto se realiza con la "intención de dañar y sin utilidad seria y legítima” ${ }^{45}$-teoría volitiva-, o cuando el acto no se ejecuta conforme a las finalidades propias del derecho -teoría funcional- ${ }^{46}$. En ese orden de ideas, para que un acto se considere abusivo, debe ser malicioso y antifuncional; el primer requisito, reitero, exige una ejecución dolosa y mal intencionada del acto por el titular del derecho de propiedad y el segundo requiere que el acto sea contrario al espíritu y la finalidad de un derecho subjetivo determinado ${ }^{47}$, en este caso, contrario al derecho de propiedad. Sin embargo, el segundo precepto ha cobrado más relevancia y ha desplazado al primer criterio que valora la intención.

En ese sentido, el abuso del derecho se traduce en la ejecución de actos innecesarios y contrarios a la finalidad propia de cada derecho subjetivo, los cuales son considerados "actos de emulación" ${ }^{48}$, y consisten en hacer uso de un derecho subjetivo sin ninguna función propia que beneficie de manera legítima a su titular; sin embargo, a pesar de que la intención pasa a un examen de segundo nivel al valorar la conducta, hay quienes continúan evaluando la intención maliciosa del actor en perjuicio de alguien más.

El abuso del derecho comenzó a ser analizado en concordancia con las obligaciones de vecindad en el ejercicio del derecho de propiedad sobre bienes inmuebles con el fin de prohibir actos inútiles del dueño del bien -teoría funcional-, y aún más, para prohibir la afectación de terceros de manera intencional -teoría volitiva-. No obstante, el rezago de la teoría volitiva permitía vedar el acto, aunque fuese ejecutado sin intención de ocasionar un daño.

Esa situación se analizó en una serie de decisiones judiciales clásicas y relevantes ${ }^{49}$ para el estudio del derecho civil en las que, habiendo o no intención maldadosa

44 Leonfanti, María Antonia. Abuso del derecho, Buenos Aires, Librería Jurídica Valerio Abeledo, 1945, p. 15.

45 Ídem.

46 Josserand, Louis. Del abuso de los derechos y otros ensayos, Bogotá, Temis, 1999, p. 5, citado por Rengifo García, Ernesto. Op. cit., p. 40: "El derecho moderno y especialmente el derecho contemporáneo se forman del abuso de una idea mucho más comprensiva; es abusivo cualquier acto que, por sus móviles y por su fin, va contra el destino, contra la función del derecho que se ejerce; el criterio puramente intencional tiende a sustituirse por un criterio funcional, derivado del espíritu del derecho, de la función que le está encomendada. Cada derecho tiene su espíritu, su objeto, su finalidad; quien quiera que intente apartarlo de su misión social, comete una falta, delictuosa o cuasidelictuosa, un abuso del derecho susceptible de comprometer, dado el caso, su responsabilidad".

47 Rengifo García, Ernesto. Op. cit., p. 22.

48 Ibíd., pp. 42-44.

49 Leonfanti, María Antonia. Op. cit., p. 15 y Rengifo García, Ernesto. Op. cit., pp. $45-46$. 
de ocasionar daño por quien ejecutó el acto, se concluyó que hubo abuso en el ejercicio del derecho de propiedad:

- En una sentencia del 2 de mayo de 1855 la Corte de Colmar, Francia, concluyó que hubo abuso del derecho cuando un propietario construyó sobre su techo una falsa chimenea sin ninguna utilidad y con un fin malicioso de quitar luminosidad a su vecino.

- En una sentencia de 1856 el Tribunal de Lyon sancionó al propietario de un terreno por haber instalado una bomba que disminuía una vertiente de agua cercana con el único fin de perjudicar a su vecino, dado que se demostró que el agua desviada no era utilizada sino desperdiciaba. El propietario fue condenado por haber actuado motivado exclusivamente por el ánimo de dañar.

- En 1901 la Corte de Sedan concluyó en una sentencia que existió abuso del derecho cuando un propietario construyó una pared de gran altura y la pintó de color negro con el fin de molestar a su vecino.

- En una sentencia del 19 de febrero de 1913, conocida como el "Caso Clement Bayard", el Tribunal de Compiègne trató el caso de una compañía denominada "Clement Bayard", dedicada a la fabricación de automóviles y dirigibles, que se vio afectada cuando un propietario colindante de uno de los hangares de dicha compañía construyó una serie de picas de madera con punta de acero que dificultaba la entrada de los dirigibles. Al respecto, el Tribunal determinó que "el titular de un derecho no puede ejercerlo para un fin distinto a aquel para el que le ha sido reconocido el legislador".

Así las cosas, la emisión de sonidos, ruidos, olores, humo, o la construcción de paredes columnas o cualquier otra adición a la estructura física de un inmueble que tuviera la potencialidad de afectar o dañar a un tercero debía revisarse sobre la base de su necesidad y finalidad dentro del ejercicio de la propiedad del dueño. Por esa razón, cuando ocurrían emisiones de olores o de humo necesarias o inevitables para su dueño, por ejemplo, provenientes de una actividad industrial, no constituía abuso del derecho a pesar de ocasionarle molestias o daños a sus vecinos, siempre que se realizara dentro del ejercicio normal de su derecho de propiedad y se hiciera de forma responsable y diligente.

En este último panorama existe una interesante providencia de los Tribunales de Santa Fe, Argentina, en materia de ruidos intolerables producidos por un establecimiento industrial dedicado a la marmolería, actividad que si bien estaba ocasionando molestias a los vecinos tenía una función útil para su propietario y, además, había sido autorizada por la municipalidad. En este caso, los Tribunales de la provincia ordenaron indemnizar a quienes habían resultado afectados, pero expresaron que la cesación de aquellos ruidos solo podía ordenarla la administración 
de la municipalidad (Jurisprudencia de los Tribunales de la Provincia de Santa Fe, Argentina/Rosario, Cámara 3a 7-XII-1933) ${ }^{50}$.

Esta línea de decisiones permite ver la evolución de la teoría funcional sobre la volitiva para entender el abuso del derecho como el ejercicio disfuncional e innecesario de un derecho subjetivo. Así, se comenzó a sustituir el requisito de la voluntad o intención en la causación de daño, por el mero requisito funcional de la verificación y calificación de un acto como abusivo.

Valencia Zea definió la teoría funcional al expresar que "[L]os derechos subjetivos de los particulares [...] obedecen a una orientación determinada, y de esos derechos se abusa cuando existiendo el deber de ejercerlos no se ejercen, o se ejercen en sentido opuesto a su propio destino o contenido"s1. Por ende, cuando no se detecte una afectación inútil promovida por el titular de un derecho de propiedad no nos encontramos frente a un abuso del derecho sino frente a un uso excesivo del mismo.

En Colombia existen múltiples fallos, tanto de la Corte Constitucional como de la Corte Suprema de Justicia, frente a los actos considerados como abusivos. De la primera corporación se destacan las Sentencia C-258 de 2013 y C-280 de 2017, decisiones que retomaron el alcance del abuso del derecho y fijaron una serie de elementos para que se configurara. $\mathrm{Al}$ respecto esas decisiones sostuvieron:

El abuso del derecho, aunque éste se halle amparado formalmente en una norma jurídica, no legítima la conducta de quien actúa en perjuicio de la colectividad o afectando los derechos ajenos. De allí que el artículo 95 de la Constitución establezca, como primer deber de la persona y del ciudadano, el de respectar los derechos ajenos y no abusar de los propios.

[...] una persona comete abuso del derecho cuando: (i) obtuvo el derecho de forma legítima, pero lo utiliza para fines contrarios al ordenamiento jurídico; (ii) se aprovecha de la interpretación de las normas o las reglas, con el fin de obtener resultados no previstos por el ordenamiento jurídico; (iii) hace un uso inadecuado e irrazonable del derecho, contrario a su contenido esencial y a sus fines; y (iv) invoca las normas de una forma excesiva y desproporcionada desvirtuando el objetivo jurídico que persiguen (cursivas fuera de texto).

De acuerdo con la Corte Constitucional, el abuso del derecho es una faceta del ejercicio de los derechos que contraviene las finalidades de una norma; no es necesario que haya dolo o culpa, sino que basta con tener un resultado que contraríe las finalidades de la ley; por eso, pareciera que la Corte Constitucional se ajusta a la avanzada teoría funcional.

50 Leonfanti, María Antonia. Op. cit., p. 14.

51 Valencia Zea, Arturo. Derecho civil. t. i, De las obligaciones, 9. a ed., Bogotá, Temis, 1998, p. 304, citado por Rengifo García, Ernesto. Op. cit., p. 53. 
En lo que respecta a la Corte Suprema de Justicia, debido al estudio de casos por la especialidad de la Sala Civil, durante años esta corporación ha tenido la oportunidad de estudiar la figura del abuso del derecho atendiendo a la teoría funcional y en ocasiones la volitiva. Una providencia destacable para este análisis es la Sentencia del 31 de agosto de 1954 de la Sala de Casación Civil de la Corte Suprema de Justicia; a partir de las bases fundamentales entregadas por Josserand, la Corte analizó los daños producidos en predios vecinos de una construcción de edificios y distinguió los tipos de actos en los que el propietario de un inmueble puede comprometer su responsabilidad y los clasificó así:

- Actos ilegales: aquellos que están fuera de los limites de la ley, es decir, ejecutados en violación de un precepto legal;

- Actos abusivos: aquellos que en concreto son ilícitos en virtud de los móviles que los inspiran. Entonces, son los ejecutados abusando del derecho son culposos.

- Actos excesivos: con fines lícitos pero perjudiciales, son ejecutados sin intención y ni siquiera con descuido, pero que a pesar de ello causan un daño al vecino.

En esta Sentencia de 1954 la Corte permeó el concepto de actos abusivos con el requisito de la intención o voluntad del titular del derecho de ocasionar daño, sin ahondar o destacar la función finalista del derecho. Adicionalmente, entregó un tipo de acto sobre el derecho de propiedad denominado "actos excesivos" que, de acuerdo con Leonfanti ${ }^{52}$, tiene fines lícitos pero efectos perjudiciales. Estos actos excesivos están bien ejemplificados en el caso de la marmolería de Santa Fe (Argentina), donde la emisión de sonidos tenía una función en beneficio de su propietario pero que, a pesar de que estaba autorizada por la municipalidad, ocasionaba perjuicios a los vecinos.

De esa forma, los actos excesivos sobre el ejercicio de un derecho requieren: i) que el acto se realice dentro de la licitud; ii) que el acto sea útil y funcional para su titular, y iii) que ocasione un perjuicio (inevitable) en el derecho de otra persona.

Con esto, es posible ver que existen varias formas de uso de los derechos sustanciales, entre ellas el ejercicio abusivo y el ejercicio excesivo; el primero consiste en desviarse de la finalidad que la ley ha establecido para un determinado derecho y termina por poner en riesgo el derecho de otro sujeto, en ese tipo de acto se puede revisar o no la intención del titular frente a la ocasión del daño; por su parte, el segundo tipo de ejercicio del derecho (uso excesivo) ocurre cuando un determinado acto se realiza dentro de una licitud y representa una utilidad o funcionalidad para el titular del derecho pero, a pesar de ello y de la diligencia con que el titular ejerza su derecho, termina por afectar el de los demás. 


\section{EL USO EXCESIVO DE LOS DERECHOS DE PROPIEDAD INDUSTRIAL}

\section{MEDIANTE MARCAS CONSTITUIDAS POR LA FORMA DEL PRODUCTO}

Como se señaló, los derechos de propiedad industrial pueden ser considerados monopolios legales exclusivos que restringen la competencia respecto de determinados bienes, servicios y procesos. Por ende, la propiedad industrial interfiere considerablemente en la competencia, concretamente restringiéndola, y aunque pareciera que dicha consecuencia fuese contraria a derecho, solo por ostentar dicho derecho, el titular de la propiedad industrial tiene una ventaja que lo ubica legítimamente en una posición diferente a la de sus competidores.

El solo hecho de poseer un derecho de propiedad industrial ya es de por sí una limitación de la competencia gracias a sus prerrogativas excluyentes y exclusivas, por eso se afirma que " $[. .$.$] los derechos de propiedad industrial, cada uno dentro$ de sus propios límites, producen un efecto de bloqueo en el mercado, toda vez que el titular puede excluir a todos los demás de la explotación del objeto sobre el que recae su derecho" ${ }^{53}$. Frente a los signos distintivos pasa lo mismo, conforme a las disposiciones de ley en sistemas registrales como el colombiano, la atribución de exclusión se adquiere mediante el registro.

Ahora bien, para comprender, a partir de un estudio de la estructura económica de esta disciplina, la función o finalidad de los derechos de propiedad industrial frente al abuso del derecho mediante la teoría funcional, es claro que la propiedad industrial y el derecho de la competencia persiguen objetivos claramente diferentes. El ejercicio legítimo de la propiedad industrial, que consiste en el uso exclusivo de determinado bien inmaterial y en la exclusión de otros competidores, no atenta contra la funcionalidad de la propiedad industrial ya que los actos relacionados con la exclusión de terceros sobre algún derecho de propiedad industrial resultan ser indispensables para su correcto y legítimo ejercicio.

La exclusión de terceros es una finalidad necesaria de la propiedad industrial para retribuir y enaltecer el esfuerzo intelectual de su creador y titular. Por lo tanto, ejercer un derecho de propiedad industrial no es considerado como un acto ilegítimo y mucho menos abusivo. La finalidad de exclusión que se deriva del ius prohibendi no es ajena a los signos representados en la forma de los productos, por más que afecten a los competidores al impedir su acceso, pues dicha exclusión sobre la forma de producto, por más que no tenga sustitutos, resulta ser una consecuencia natural para el titular del derecho. En ese sentido, la facultad de exclusión en el uso de la propiedad industrial no podría ser considerada abusiva, por cuanto: i) el titular obtuvo el derecho de forma legítima y no lo utiliza para fines contrarios al ordenamiento jurídico, y ii) el titular del signo no hace un uso inadecuado e irrazonable del derecho, o contrario a su contenido esencial y a sus fines, sino que, por el contrario, lo usa en la forma que la ley se lo permite.

53 Otero lastres, José Manuel. Op. cit., 63. 
Para llegar a esta conclusión es necesario examinar rápidamente tanto la finalidad como la función del derecho de propiedad industrial sobre las marcas (tradicionales y no tradicionales). Algunos autores, entre ellos Fernández Novoa, sostienen que la función principal de la marca es distinguir entre productos y servicios como indicadores de la procedencia empresarial: "[E]sta función fundamental y primaria de la marca es poner de manifiesto ante el público que los productos (o servicios) portadores de la marca proceden de una determinada empresa" 54 . De esa primera función se desprenden otras aleatorias, como la función indicadora de calidad y la función publicitaria. Sin embargo, más allá de las funciones comerciales de la marca, existe un objetivo concreto que se desprende de este derecho denominado "objeto de la marca", concepto adoptado, entre otros, por el Tribunal de Justicia de Luxemburgo ${ }^{55}$, el cual consiste en tener como parte integral (y principal) de la funcionalidad de la marca la facultad de impedirle a terceros el uso del signo, esto con el fin de que no desaparezcan las demás funciones de la marca (la función indicadora del origen y calidad y la función publicitaria).

Landes sostiene que " $[\mathrm{U}] \mathrm{n}$ derecho de propiedad industrial consiste en la facultad jurídicamente protegida de excluir a otras personas de la utilización de un recurso: cualquier tercero es excluible [...]" ${ }^{\prime \prime}$, de esta forma, las restantes funciones de la marca pertenecen a un plano importante pero secundario dado que, si no se impide a otros sujetos el uso del signo protegido mediante propiedad industrial, las demás funciones estarían eliminadas o en riesgo de desaparecer. Por lo tanto, la función principal del "objeto de la marca" es excluir (ius prohibendi) -teoría funcional-y su ejercicio no puede ser considerado abusivo.

De esa forma, y como gran conclusión, queda claro que al ser la exclusión la función principal de la propiedad industrial, apropiarse de forma legítima de la forma de un producto como marca y posteriormente impedir que otro sujeto lo utilice, no significa violentar la finalidad del derecho de propiedad; en otras palabras, oponerse y limitar a los competidores el uso de un signo va acorde con la finalidad propia del derecho industrial y con su función, por lo tanto, no se considera un abuso. Es por eso que, de acuerdo con la teoría funcional, el monopolio económico que se deriva de la apropiación de una forma que representa la forma de un producto único en el mercado, mediante el cual se obstruye, limita e impide el ingreso de agentes a un mercado, no puede ser considerado como un abuso del derecho sino como un acto excesivo por cuanto el derecho de propiedad industrial se obtuvo de forma legítima, se usa conforme a su finalidad subjetiva y no va en contra del ordenamiento jurídico.

54 Fernández-Novoa, Carlos. “Nociones básicas”, en Fernández-Novoa, Carlos, Otero lastres, José Manuel y Botana Agra, Manuel. Op. cit., 490.

55 Luxemburgo. Tribunal de Justicia de Luxemburgo. Sentencia del 23 de mayo de 1978, caso Hoffman-La Roche/Centrafarm.

56 Landes, William M. y Posner, Richard. Op. cit., p. 22. 
De esa manera, adquirir como signo la forma de un producto y limitar a otros su uso no es un ejercicio inadecuado e irrazonable del derecho, no es contrario a su contenido esencial, sino que lo usa en la forma en que la ley se lo permite, sin embargo, al tener fines lícitos pero perjudiciales para sus competidores, es considerado excesivo.

\section{CONCLUSIONES}

La naturaleza jurídica de la propiedad industrial se permea ineludiblemente de las características propias del derecho de propiedad clásico, el cual fue el primero en entregarle a esta disciplina las prerrogativas absolutas y exclusivas de cualquier derecho de propiedad; sin embargo, el calificativo "industrial" es el que potencializa este derecho alejándolo de cualquier derecho de propiedad simple o común para dotarlo de una especialidad derivada del objeto de protección (bienes inmateriales) y de la vinculación de aquellos bienes con el mercado y la competencia.

La vinculación de los bienes protegidos mediante propiedad industrial con el mercado y la competencia surge de las facultades esenciales que el titular de un derecho de propiedad industrial, especialmente de una marca, tiene sobre ella, las cuales se resumen en la facultad de aplicar la marca en el producto, la facultad de ponerla en el comercio y la facultad de emplear la marca en la publicidad.

La vinculación de los derechos de propiedad industrial con el mercado y con la competencia representa la existencia de un monopolio legal sobre el uso de esos derechos como consecuencia de su explotación exclusiva; no obstante, esa exclusividad constituye un bloqueo que afecta de alguna manera la competencia, pero que no se puede considerar una afectación ilegítima debido a las concesiones del derecho de propiedad industrial. Sin embargo, una afectación de la competencia como resultado del ejercicio de un derecho de propiedad industrial puede ser obstructiva y dañina cuando se trata de formas de productos que no tienen sustitutos en el mercado y son protegidos mediante marcas de tipo tridimensional, escenario en el cual se podría estructurar una estricta barrera de entrada al mercado en el que se utilice esa forma de producto.

Esta conducta enfocada en la apropiación de formas de productos mediante derechos de propiedad industrial es obstructiva de la competencia, y lleva a tres principales escenarios de análisis: el abuso de la posición de dominio, en el que se puede incluir el análisis desde la competencia desleal; el abuso del derecho como principio clásico del derecho, y el uso excesivo del derecho como calificación adicional de conducta.

Respecto del abuso de posición de dominio confrontada con la apropiación de formas sin sustitutos, encontramos que, si bien puede existir un estado de dominio como consecuencia de la apropiación exclusiva de una forma de producto, no hay lugar a su condena ya que bajo el régimen de competencia colombiano la conducta no encaja en ninguna de las seis hipótesis de abuso de posición de dominio 
previstas en el artículo 50 del Decreto 2153 de 1992. De igual forma, se puede concluir que las acciones de competencia desleal no son suficientes para eliminar el impacto derivado del uso de una forma de producto protegida con derechos de propiedad industrial mientras el derecho esté concedido y en firme mediante un acto respaldado de legalidad.

Por otro lado, en principio se puede llegar a pensar que la apropiación de una forma de producto sin sustitutos mediante la propiedad industrial y la exclusión de terceros constituyen un uso abusivo del derecho, pero dicha conclusión se descarta cuando se determina que el derecho de propiedad industrial no tiene otra finalidad esencial que excluir. Por lo tanto, eso nos lleva a estar frente a otra situación en la que, aunque genere un perjuicio a otra persona (competidor), el ejercicio del derecho se realiza dentro de la licitud, siendo útil y funcional para su titular, características que son propias del uso excesivo de un derecho el cual requiere: i) que el acto se realice dentro de la licitud; ii) que el acto sea útil y funcional para su titular, y iii) que inminentemente ocasione un perjuicio en el derecho de otra persona.

De esa manera, apropiarse de una forma de un producto que resulta ser única en su categoría, sin sustitutos que satisfagan la misma necesidad para los usuarios o consumidores, para luego privar de su uso a los competidores como resultado de las prerrogativas propias del ius prohibendi o derecho de exclusión, no resulta ser una conducta contraria a las finalidades del derecho industrial, por lo que no puede ser considerada como abusiva sino como excesiva.

\section{REFERENCIAS}

Arboleda Suárez, Carlos Ignacio. "El abuso de la posición de dominio en Colombia", Revista de Derecho de la Competencia, Centro de Estudios de Derecho de la Competencia (CEDEC), Vol. 13, n. ${ }^{\circ} 13$, Bogotá, Pontificia Universidad Javeriana, pp. 111-134.

Castro García, Juan David. "Las marcas no tradicionales", Revista La Propiedad Inmaterial, n. ${ }^{\circ} 16,2012$, pp. 297-325.

Código Civil Colombiano. Ley 84 de 1873, Diario Oficial n. ${ }^{\circ} 2.867$ de 31 de mayo de 1873.

Congreso de la República. Proyecto de Ley n. 38 de 2015, "por medio del cual se introducen modificaciones al régimen de protección de la competencia, a las funciones de la Superintendencia de Industria y Comercio, y se dictan otras disposiciones".

Constitución Política de la República de Colombia, 1991.

Corte Constitucional. Sentencia C-258 de 2013.

Corte Constitucional. Sentencia C-280 de 2017.

Corte Suprema de Justicia. Sala de Casación Civil. Sentencia del 31 de agosto de 1954. 
Ministerio de Desarrollo Económico. Decreto 2153 de 1992, Diario Oficial n. ${ }^{\circ} 40.704$ del 31 de diciembre de 1992.

Superintendencia de Industria y Comercio. Resolución 40912 de 2012. Superintendencia De Industria y Comercio. Resolución n.o 3694 de 2014. Superintendencia de Industria y Comercio. Resolución n. 4907 de 2013. Comunidad Andina. Decisión 486 de 2000, Régimen Común sobre Propiedad Industrial.

Comunidad Andina. Tribunal Andino de Justicia. Proceso 153-IP-2005, Gaceta Oficial del Acuerdo de Cartagena n. ${ }^{\circ} 1284$ del 13 de enero de 2006. Actor: Parke, Davis \& Co. Limited. Marca: "Halitos".

Comunidad Andina. Tribunal Andino de Justicia. Proceso 33-IP-2005, Gaceta Oficial del Acuerdo de Cartagena n. ${ }^{\circ} 1284$ del 2 de agosto de 2005. Actor: Bavaria S.A. Marca: "Forma de Botella".

Comunidad Andina. Tribunal Andino de Justicia. Proceso 31-IP-2003, Gaceta Oficial del Acuerdo de Cartagena n.o 960 del 1. . $^{\circ}$ de agosto de 2003.

De la Cruz, Dionisio. La competencia desleal en Colombia. Un estudio sustantivo de la ley, 2. a ed., Bogotá, Universidad Externado de Colombia, 2020, pp. 21-37. Fernández-Novoa, Carlos. Tratado sobre Derecho de Marcas, 2. ${ }^{a}$ ed., MadridBarcelona, 2004, p. 755.

Gómez Segade, José Antonio. El secreto industrial (know-how). Concepto y protección, citado por Otero Lastres, José Manuel. "Introducción", en Fernández-Novoa, Carlos, Otero Lastres, José Manuel y Botana Agra, Manuel. Manual de la Propiedad Industrial, Madrid-Barcelona-Buenos Aires, Marcial Pons, 2009, p. 847.

Guerrero Gaitán, Manuel, Payán Rodríguez, Carlos Felipe y Velazco Ordóñez, Pablo. El nuevo Derecho de marcas: perspectiva en Colombia, Estados Unidos y la Unión Europea, Bogotá, Universidad Externado de Colombia, 2016, p. 358.

Herrera Sierra, Luisa. “¿Cuál es la adecuada extensión de los derechos de propiedad intelectual?: comentarios sobre el derecho marcario", Competencia Económica y Consumo, Departamento de Propiedad Intelectual, Bogotá, Universidad Externado de Colombia, 9 de junio de 2019.

Landes, William M. y Posner, Richard A. The Economic Structure of Intellectual Property Law, Sánchez Álvarez, Víctor Manuel (trad.), Madrid, Fundación Cultural del Notario, 2006, p. 575.

Leonfanti, María Antonia. Abuso del derecho, Buenos Aires, Librería Jurídica Valerio Abeledo, 1945, p. 121.

Luxemburgo. Tribunal de Justicia de Luxemburgo. Sentencia del 23 de mayo de 1978, caso Hoffman-La Roche/Centrafarm.

Metre Méndez, Ricardo. Lecciones de propiedad industrial, Medellín, Diké, 2006, p. 216. 
Miranda Londoño, Alfonso. "El Régimen General de la Libre Competencia. Características principales", en Segundo Congreso Iberoamericano de Derecho Empresarial. Formas de control, colaboración, competencia empresarial y propiedad industrial, Bogotá, octubre de 1997.

Ortiz Justiniano, Catalina. "La intencionalidad en el concepto de abuso en el derecho privado y en libre competencia", Memoria de prueba para optar al grado de licenciado en ciencias jurídicas y sociales, Santiago de Chile, Universidad de Chile, p. 181.

Rengifo García, Ernesto. Del abuso del derecho al abuso de la posición dominante, 2. a ed., Bogotá, Universidad Externado de Colombia, 2004, p. 472.

Rey-Alvite Villar, Manuel. "El carácter distintivo de la marca tridimensional en la jurisprudencia de la Unión Europea", Cuadernos de Derecho Transnacional, Vol. 6, n. ${ }^{\circ}$ 1, p. 294-329.

Valencia Zea, Arturo. Derecho civil, t. i, De las obligaciones, 9. a ed., Bogotá, Temis, 1998.

Velandia, Mauricio. Derecho de la competencia y del consumo. Competencia desleal; abuso de la posición de dominio; carteles restrictivos; actos restrictivos; integraciones económicas y protección al consumidor, 2. ${ }^{\mathrm{a}}$ ed., Bogotá, Universidad Externado de Colombia, 2011, p. 250.

Velázques Jaramillo, Luis Guillermo. Bienes, Bogotá, Temis, 2004, p. 519. 